\title{
Nursing Students' Perception of Childhood Lead Poisoning Risk
} Factors

\author{
Sarah Morrison ${ }^{1}$, Elizabeth Ressler ${ }^{2}$, Krystina Sheets $^{3}$ \& Sam Abraham ${ }^{4}$ \\ ${ }^{1}$ Maternity, Munson Medical Center, Traverse City, MI, USA \\ ${ }^{2}$ Critical Care, Saint Joseph Regional Medical Center, Mishawaka, IN, USA \\ ${ }^{3}$ Medical-Surgical and OB, Community Hospital of Bremen, Bremen, IN, USA \\ ${ }^{4}$ School of Nursing, Bethel College, Mishawaka, IN, USA \\ Correspondence: Sam Abraham, Assistant Professor of Nursing, Bethel College, Indiana, 46545, USA.
}

Received: October 17, 2017

doi:10.20849/ijsn.v2i2.216
Accepted: November 5, $2017 \quad$ Online Published: November 13, 2017

URL: https://doi.org/10.20849/ijsn.v2i2.216

\begin{abstract}
Background: Adverse effects on health in the environments are no trivial matter. Exposure to lead has had devastating consequences for health, especially for children. The purpose of this study was to investigate nursing students' perception of childhood lead poisoning risk factors.

Methods: This was a quantitative, cross-sectional study with a descriptive design. Data were collected from 85 baccalaureate nursing students in a college situated in Northern Indiana, USA.

Results: The top five most agreed upon responses, chipping or peeling paint; learning problems; blood testing; inedible objects; and lead removal, had means greater than 4.18, on a 5-point Likert-type scale, which indicates a high level of agreement.

Discussion: Some of the survey statements indicated deficits in nursing students' knowledge of lead poisoning risk factors requiring further teaching and learning.

Conclusions: More education related to childhood lead poisoning risk factors may need to be integrated into courses such as nursing fundamentals, pediatrics, and community health.
\end{abstract}

Keywords: lead poisoning risk factors, childhood lead poisoning, children and lead

\section{Introduction and Background}

Healthy People 2020 recognizes lead poisoning as a public health concern because it is not an element necessary for the human body (Burns et al., 2012). The CDC (2012) defines elevated blood lead level (EBLL) as greater than or equal to $5 \mathrm{mcg} / \mathrm{dl}$, as determined by a blood test. Exposure to lead has had devastating consequences for health, especially for children. Exposure to lead in high levels could affect the brain, academic performance, the central nervous system and cause seizures, coma, and even death (Miranda, Anthopolos, \& Hastings, 2011; Raymond, Anderson, Feingold, Homa, \& Brown, 2009; Zhang et al., 2013). Training the public does help to reduce exposure to lead poisoning (Phoenix, Green, \& Thompson, 2013). However, not all nursing curriculum has in-depth teaching about this entirely preventable disease. The purpose of this study was to investigate nursing students' perception of childhood lead poisoning risk factors. The research question for this study was, "What is nursing students' perception of childhood lead poisoning risk factors."

Campbell, Greenberg, Mankikar, and Ross (2016) highlighted that the failure of Flint, Michigan, United States, to treat its city water system after a change in the source of water caused increased levels of lead. This resulted in elevated blood lead levels in children. Multiple levels of government failed to protect public's health, thus, endangering the health of residents. This is a good example of the need for vigilance in protecting and promoting environmental health (Campbell et al., 2016).

\section{The Literature Review}

Public's perception of lead poisoning was explored through literature search because there were no research regarding nursing students' perception of childhood lead poisoning in the searched databases. Online databases used included Academic Search Premier, Cumulative Index of Nursing and Allied Health Literature (CINAHL), 
and EBSCOhost. Search phrases used were childhood lead poisoning, childhood lead poisoning risk factors, children and lead, and lead and risk factors.

\subsection{Link to $A D H D$}

A strong link has been found between attention deficit hyperactivity disorder (ADHD) and the presence of elevated blood lead levels (EBLLs), which contribute to educational deficits (Zhang et al., 2013). Neurological harm, such as hearing loss, has been attributed to EBLLs. EBLLs have been found in children living in areas containing environmental hazards, such as lead-based paints, pipes, natural remedies, soil contaminants, and industrial hazards (Zhang et al., 2013). Raymond et al. (2009) found an association between late-onset childhood lead poisoning, demographic, environmental, and medical risk factors. Black males between three and four years old whose immunizations were not current were more likely to have EBLLs (Raymond et al., 2009).

\subsection{High Risk Geographical Areas}

Roberts, Allen, Ligon, and Reigart (2012) sought to determine the blood lead level (BLL) of children in high-risk geographical areas and risk factors that predispose one to a BLL. The results did not indicate a lack of knowledge for any of the participants but did reveal a general unawareness of the lack of medication to treat lead poisoning and the asymptomatic nature of lead poisoning in children. Robert et al. found, $29 \%$ of the homes evaluated had lead risk factors present. Geographically targeted screening should be implemented as questionnaires, and community-based screening may not adequately identify children with BLL below $10 \mu \mathrm{g} / \mathrm{dL}$ (Roberts et al., 2012). Vivier et al. (2011) pursued to determine the geographical location in relation to childhood BLLs. Variables included geographical location, age, gender, test method, poverty level, and residence in a pre-1950s house. The results reflected both poverty status and residence in a pre-1950 home to be independent risk factors for BLL (Vivier et al., 2011).

\subsection{Building Contractors Training}

Blando, Antoine, and Lefkowitz (2013) conducted a study to understand what building contractors and the community knew about lead and the risks of lead poisoning. Blando et al. determined that contractors performed procedures that created dust and therefore, a lead exposure threat. Contractors were found to have little awareness of this hazard. An adequate public knowledge of the hazard of lead-based paint in the home was found; however, the child's primary provider did not conduct the required risk assessments for lead exposure (Blando et al., 2013). Phoenix et al. (2013) identified children under the age of six to have harsher effects from lead poisoning than any other age group, most commonly from distressed lead paint in homes. Training of the contractors, realtors, and the community help to enhance their actions to reduce lead exposure (Phoenix et al., 2013).

\subsection{Early Childhood Exposure}

Boucher et al. (2012) found that lead exposure in children has been linked to attention deficit and disruptive behaviors. Early childhood exposure to lead was negatively correlated with academic success in junior high and elementary school, after eliminating confounding variables (Zhang et al., 2013). Children are at an increased risk for mental and psychomotor delays with a co-exposure to lead and manganese (Henn et al., 2012).

\subsection{Living near Airports}

Miranda et al. (2011) focused on a study to determine the effects of airplane gasoline on a child's blood lead level, to decide if the BLLs had a corresponding relationship with the proximity of a child's home to an airport. EBLLs did have a noteworthy level of association in children who lived within 500 meters of the airport. This was also found to be true, with significance lessoning as the distance greatened, in children living 1,000 and 1,500 meters from an airport (Miranda et al., 2011).

\subsection{Summary of Literature Review}

In summary, childhood lead poisoning remains a concern. Dyal (2011) stated, "Over 300,000 children aged 5 years or younger and over 1 million adolescents have elevated blood lead levels" (p. 3). Additionally, Vivier et al. (2011) stated, "Even low levels of lead poisoning are associated with irreversible, deleterious effects on a child's development leading to learning and behavioral disorders, hearing impairment, decreased intelligence quotient (IQ), and diminished attention span" (p. 1196). The above literature review reflects a thorough analysis of the available research findings. The presence of EBLLs in children is associated with a variety of behavioral, cognitive, and developmental complications. Accurate knowledge of lead poisoning risk factors is crucial to the prevention and early detection of childhood lead poisoning. Thus, the need to investigate nursing students' perception of childhood lead poisoning risk factors to determine if further teaching and learning are necessary. 


\section{Methodology}

The chosen method was quantitative, cross-sectional, with a descriptive design. The participants were a convenience sample of 85 baccalaureate degree nursing students' age 18 or older in a college located in Northern Indiana. The college consisted of a population of 2000 students of which about 160 were in the nursing baccalaureate program. The survey instrument was developed after a thorough review of the literature. Two peers and two nursing faculty members reviewed the instrument to determine its face validity. The survey instrument consisted of 5 demographic and 18 survey statements on a 5-point Likert-type scale based on levels of agreement ranging from 1 (Strongly Disagree) to 5 (Strongly Agree). The College Institutional Review Board had approved the study before the survey process began. The informed consent given to the participants contained information about the purpose and the potential educational benefits of the study; participants signed it prior to taking the survey.

Contained within the survey were statements relating to lead poisoning risk factors, prevention, effects, and diagnosis. Items correlating with risk factors and prevention included topics such as drinking water, paint removal, keys, nutrition, medication, soil, and housing. Items corresponding to lead poisoning effects included signs of illness, behavioral problems, and learning impairments. The diagnosis statement corresponded with blood tests. To increase validity, only questions directly relating to lead poisoning risk factors were included.

Permission was obtained to conduct the surveys outside the college Dining Commons. Participants had the freedom to answer survey questions before or after their meals. A table was set up with survey sheets and informed consents, as well as candy to help give individuals the initiative to participate in the study. Each individual willing to participate was given explanation regarding the informed consent and requested to sign it before completing the survey. The participants' names were not written on the survey document, therefore, keeping information confidential. Participants received a copy of the informed consent. Upon completion of the survey, the informed consent and the surveys were placed in separate manila envelopes.

\section{Results}

One primary research question guided this study: What is students' perception of risk factors contributing to lead poisoning? The results of the analyses appear in the following sections. The mean for survey statements and the standard deviation was calculated. The standard deviation took into account the values of each score and provided a comparison between scores. An ordinal level of measurement for the questionnaire data were used because the survey was based on a Likert-type scale. The nominal level of measurement was used for the demographic data.

\subsection{Demographic Characteristics}

Eighty-five nursing students participated in this study. This was more than $50 \%$ of the baccalaureate student population in the School of Nursing. In Table 1, the participants' demographic and background characteristics are explained using a descriptive statistical method; including the frequency $(f)$ and percentage (\%). A high percentage of the participants were between the ages of 18-24 (87\%). The majority of participants were female $(92.9 \%)$. The sophomores, juniors, and the seniors were somewhat, equally divided in their participation. 
Table 1. Descriptive statistics for participant demographics and background

\begin{tabular}{|c|c|c|}
\hline Variable & $f$ & $\%$ \\
\hline \multicolumn{3}{|l|}{ Age } \\
\hline $18-24$ & 74 & 87.0 \\
\hline $25-31$ & 5 & 5.9 \\
\hline 32 and above & 6 & 7.1 \\
\hline \multicolumn{3}{|l|}{ Gender } \\
\hline Male & 6 & 7.1 \\
\hline Female & 79 & 92.9 \\
\hline \multicolumn{3}{|l|}{ Program Year } \\
\hline Sophomore & 26 & 30.6 \\
\hline Junior & 30 & 35.3 \\
\hline Senior & 29 & 34.1 \\
\hline \multicolumn{3}{|l|}{ Race } \\
\hline Asian & 2 & 2.4 \\
\hline White & 78 & 91.7 \\
\hline Mixed & 2 & 2.4 \\
\hline Other & 3 & 3.5 \\
\hline \multicolumn{3}{|l|}{ Childhood Home Built } \\
\hline Before 1950 & 21 & 24.7 \\
\hline After 1950 & 64 & 75.3 \\
\hline \multicolumn{3}{|l|}{ Childhood Household Income } \\
\hline Less than $\$ 19,999$ & 2 & 2.4 \\
\hline$\$ 20,000$ to $\$ 39,999$ & 22 & 25.9 \\
\hline$\$ 40,000$ to $\$ 59,999$ & 26 & 30.6 \\
\hline$\$ 60,000$ or more & 35 & 41.1 \\
\hline
\end{tabular}

Note. $(N=85)$

The White race was most prominent among participants (91.7\%). Most participants' childhood homes were built after 1950 (75.3\%), with $24.7 \%$ being built before 1950 . The most common childhood household income was $\$ 60,000$ or more $(41.1 \%)$, followed by $\$ 40,000$ to $\$ 59,999(30.6 \%), \$ 20,000$ to $\$ 39,999(25.9 \%)$, and a small number of participants with less than $\$ 19,999$ (2.4\%).

4.2 Nursing Students'Perception of Childhood Lead Poisoning Risk Factors

All the survey statements focused on the participants' knowledge of risk factors contributing to lead poisoning. 
Topics for the risk factors included blood testing, medications, drinking water, learning problems, old homes, proper nutrition, signs of illness, tap water, hand washing, lead removal, behavior problems, soil, personal or family experience, houses built before 1950, keys, digestive aids, chipping or peeling paint, and inedible objects.

Table 2. Perception of risk factors affecting childhood lead poisoning

\begin{tabular}{|c|c|c|}
\hline Variable & $M$ & $S D$ \\
\hline $\begin{array}{l}\text { Chipping or peeling paint off walls, doors, and windowsills will increase a } \\
\text { child's risk of lead poisoning. }\end{array}$ & 4.38 & 0.65 \\
\hline Learning problems can be caused by lead poisoning. & 4.36 & 0.72 \\
\hline Lead poisoning can be confirmed through a blood test. & 4.35 & 0.61 \\
\hline $\begin{array}{l}\text { Children who put inedible objects in their mouth are at increased risk of } \\
\text { lead poisoning. }\end{array}$ & 4.22 & 0.68 \\
\hline It is safest not to undertake lead removal on your own. & 4.19 & 0.88 \\
\hline Proper nutrition can decrease the risk of lead poisoning. & 4.14 & 0.76 \\
\hline Drinking water can contain lead. & 3.92 & 0.74 \\
\hline Signs of illness will accompany lead poisoning. & 3.52 & 1.05 \\
\hline A way to protect against lead poisoning is to wash hands before eating. & 3.40 & 1.09 \\
\hline Certain digestive aids increase a child's risk for lead poisoning. & 2.95 & 0.77 \\
\hline Behavior problems can be caused by lead poisoning. & 2.91 & 1.08 \\
\hline Only very old homes contain lead. & 2.65 & 1.18 \\
\hline $\begin{array}{l}\text { Warm tap water can be used to mix baby formula without the risk of lead } \\
\text { poisoning. }\end{array}$ & 2.44 & 0.87 \\
\hline It is okay to allow children to play with keys. & 2.25 & 1.08 \\
\hline Lead poisoning can be prevented by taking medications. & 2.24 & 0.90 \\
\hline It is safe to allow children to play in soil near an old building. & 1.82 & 0.74 \\
\hline $\begin{array}{l}\text { Children living in houses built before } 1950 \text { have a decreased lead } \\
\text { poisoning risk. }\end{array}$ & 1.60 & 0.93 \\
\hline Myself, or a family member, has had lead poisoning symptoms. & 1.39 & 0.51 \\
\hline
\end{tabular}

Note. $(N=85)$.

Items were rated on a 5-point Likert-type scale ranging from 1 (Strongly Disagree) to 5 (Strongly Agree), so higher means indicate higher levels of agreement.

Table 2 contains the mean calculations for each of the 18 statements about risk factors and is ranked by level of agreement. Items with a mean greater than 3 indicate participants, in general, tended to agree with the statements. The most strongly agreed upon statement related to chipping or peeling paint, "Chipping or peeling paint off walls, doors, and windowsills will increase a child's risk of lead poisoning" $(M=4.38, S D=0.65)$. Participants also tended to strongly agree with the items related to learning problems $(M=4.36, S D=0.72)$ and blood testing $(M=4.35, S D=0.61)$. Other statements with a high level of agreement related to inedible objects $(M=4.22, S D$ 
$=0.68)$, lead removal $(M=4.19, S D=0.88)$, behavior problems $(M=4.14, S D=0.76)$. A statement with a moderate level of agreement related to drinking water $(M=3.92, S D=0.74)$.

Statements with neutral levels of agreement related to signs of illness $(M=3.52, S D=1.05)$, hand washing $(M=$ $3.4, S D=1.09)$, digestive aids $(M=2.95, S D=0.77)$, proper nutrition $(M=2.91, S D=1.08)$, and old homes $(M$ $=2.65, S D=1.18)$. A statement with a moderate level of disagreement related to tap water $(M=2.44, S D=0.87)$. Statements with low levels of agreement included keys $(M=2.25, S D=1.08)$, medications $(M=2.24, S D=0.9)$, soil $(M=1.82, S D=0.74)$, and houses built before $1950(M=1.6, S D=0.93)$. The statement with the lowest level of agreement was related to personal or family experience, "Myself, or a family member, has had lead poisoning symptoms" $(M=1.39, S D=0.51)$. The results indicated a high level of awareness among nursing students in the areas relating to chipping or peeling paint, learning problems, blood testing, inedible objects, and lead removal. The next section contains a discussion of the study findings.

\section{Discussion}

The problem identified was the lack of research regarding nursing students' perception of lead poisoning risk factors. Research suggests a knowledge deficit of the public regarding lead poisoning (Roberts et al., 2012). Upon review of the literature using the identified keywords, no current research emerged specifically targeting nursing students' knowledge of lead poisoning. Performing this study helped narrow the literature gap, and allow the advancement of strategies to increase awareness of lead poisoning risk factors.

The top five strong agreements on risk factors, based on the results, were (a) chipping or peeling paint, (b) learning problems, (c) blood testing, (d) inedible objects, and (e) lead removal. A review of the literature found similar results relating to distressed paint containing lead in homes and lead poisoning (Phoenix et al., 2013). Zhang et al. (2013) found a correlation between lead poisoning and learning problems. The participants' responses indicated an agreement with the current practices of confirming EBLLs through blood testing (CDC, 2012). An agreement with the literature was also found in the responses relating to inedible objects contributing to lead poisoning (Raymond et al., 2009). Blando et al. (2013) suggest specific practices are required for the removal of lead-based paint, which was in agreement with the participants' responses.

The participants in this study agreed that chipping and peeling paint off walls, doors, and windowsills increases a child's risk for lead poisoning $(M=4.38)$. Phoenix et al. (2013) found distressed paint in homes does contribute to an increased risk for lead poisoning. Paint particles, which can be stirred up by construction workers has been shown to be a lead exposure threat (Blando et al., 2013).

Learning problems was viewed by the participants as having a strong correlation with lead poisoning $(M=4.36)$. This result from a study performed by Zhang et al. (2013) also revealed an association between lead poisoning and leaning problems. "Even low levels of lead poisoning are associated with irreversible, deleterious effects on a child's development leading to learning and behavioral disorders" (Vivier et al., 2011, p. 1196).

The participants viewed children placing inedible objects in their mouth as having an increased risk of lead poisoning $(M=4.22)$. In a study performed by Raymond et al. (2009), a relationship between environmental hazards and lead poisoning was found. Roberts et al. (2012) found a high association between lead poisoning and inedible objects, such as keys, dirt, or paint chips.

The participants stated a high level of agreement in regards to not attempting to remove lead from the home on their own $(M=4.19)$. Attempting to remove lead without professional help may not be effective. Blando et al. (2013) suggested specific practices should be used to decrease the risk of lead poisoning. The study by Phoenix et al. (2013) identified the harshest effects from lead poisoning most commonly to arise from distressed lead paint in homes.

Because the results indicate a slight lack of awareness surrounding childhood lead poisoning risk factors in nursing students, a lack of awareness may be present in other populations. Nurses have the responsibility to be patient advocates, which includes providing necessary education about health problems. Childhood lead poisoning has been found to cause many health issues, thus making it an important educational topic (Zhang et al., 2013). Recommendations relate to (1) the need for a change in practice at the school of nursing level and (2) the need for future research to prompt further investigation of the study findings.

\section{Conclusion}

The researchers conducted a thorough literature review, which revealed ample information on childhood lead poisoning risk factors. Parental knowledge was prevalent in the review, but research regarding nursing students' perception of risk factors was lacking. The participants' knowledge of lead poisoning risk factors closely aligned with the current research and the literature. The entire top five most agreed upon responses, chipping or peeling 
paint; learning problems; blood testing; inedible objects; and lead removal, had means greater than 4.18, on a 5-point scale, which indicated a high level of agreement. This level of agreement, when compared to the current literature, supported an accurate awareness of the participants' knowledge of lead poisoning risk factors.

The remainder of the survey statements indicated deficits in nursing students' knowledge of lead poisoning risk factors. It is proposed that a lack of education may have contributed to this level of awareness. More education related to childhood lead poisoning risk factors may need to be integrated into the nursing program curriculum. The educational material could be integrated into courses such as nursing fundamentals, pediatrics, and community health.

\section{References}

Blando, J. D., Antoine, N., \& Lefkowitz, D. (2013). Lead-based paint awareness, work practices, and compliance during residential construction and renovation. Journal of Environmental Health, 75(9), 20-27.

Boucher, O., Jacobson, S. W., Plusquellec, P., Dewailly, E., Ayotte, P., Forget-Dubois, N., ... Muckle, G. (2012). Prenatal methylmercury, postnatal lead exposure, and evidence of attention deficit/hyperactivity disorder among Inuit children in Arctic Quebec. Environmental Health Perspectives, 120(10), 1456-1461. https://doi.org/10.1289/ehp.1204976

Burns, M. S., Shah, L. H., Marquez, E. R., Denton, S. L., Neyland, B. A., Vereschzagin, D., \& Gerstengerger, S. L. (2012). Efforts to identify at-risk children for blood lead screening in pediatric clinics- Clark County, Nevada. Clinical Pediatrics, 51(11), 1048-1055. https://doi.org/10.1177/0009922812458352

Campbell, C., Greenberg, R., Mankikar, D., \& Ross, R. D. (2016). A case study of environmental injustice: The failure in Flint. International Journal of Environmental Research and Public Health, 13(10), 951. http://doi.org/10.3390/ijerph13100951

CDC. Center for Disease Control and Prevention. (2013). Standard surveillance definitions and classifications. Retrieved from http://www.cdc.gov/nceh/lead/data/definitions.htm

Dyal, B. (2011). Are lead risk questionnaires adequate predictors of blood lead levels in children? Public Health Nursing, 29(1), 3-10. https://doi.org/10.111/j.1525-1446.2011.00961.x

Henn, B. C., Schnaas, L., Ettinger, A. S., Schwartz, Z., Lamadrid-Figueroa, H., \& Tellez-Rojo, M. M. (2012). Associations of early childhood manganese and lead coexposure with neurodevelopment. Environmental Health Perspectives, 120(1), 126-131. https://doi.org/10.1289/ehp.1003300.

Miranda, M., Anthopolos, R., \& Hastings, D. (2011). A geospatial analysis of the effects of aviation gasoline on childhood blood lead levels. Environmental Health Perspectives, 119(10), 1513-1516. https://doi.org/10.1289/ehp.10O3231

Phoenix, J. A., Green, R. D., \& Thompson, A. M., (2013). Can realtor education reduce lead exposures for vulnerable populations? Journal of Environmental Health, 76(1), 28-36.

Raymond, J., Anderson, R., Feingold, M., Homa, D., \& Brown, M. (2009). Risk for elevated blood lead levels in 3- and 4-year-old children. Maternal \& Child Health Journal, 13(1), 40-47. https://doi.org/ 10.1007/s10995-007-0297-x

Roberts, J. R., Allen, C. L., Ligon, C., \& Reigart, J. R. (2012). Are children still at risk for lead poisoning? Clinical Pediatrics, 52(2), 125-130. https://doi.org/10.1177/0009922812464549

Vivier, P. M., Hauptmen, M., Weitzen, S. H., Bell, S., Quilliam D.N., \& Logan, J. R. (2011). The important health impact of where a child lives: Neighborhood characteristics and the burden of lead poisoning. Maternal Child Health, 15(1), 1195-1202. https://doi.org/10.1007/s10995-010-0692-6

Zhang, N., Baker, H. W., Tufts, M., Raymond, R. E., Salihu, H., \& Elliot, M. R. (2013). Early childhood lead exposure and academic achievement: Evidence from Detroit public schools, 2008-2010. American Journal of Public Health, 103(3), 72-377. https://doi.org/10.2105/AJPH.2012.301164

\section{Copyrights}

Copyright for this article is retained by the author(s), with first publication rights granted to the journal.

This is an open-access article distributed under the terms and conditions of the Creative Commons Attribution license (http://creativecommons.org/licenses/by/4.0/). 